Revista Tecné, Episteme y Didaxis: TED. Año 2014, Número Extraordinario. ISSN Impreso: 0121-3814, ISSN web: 2323-0126

Memorias, Sexto Congreso Internacional sobre Formación de Profesores de Ciencias. 08 al 10 de octubre de 2014, Bogotá

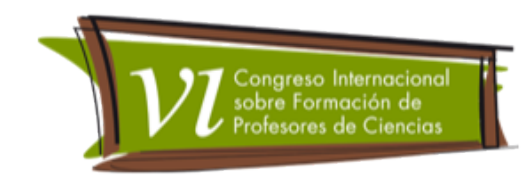

\title{
Enseñanza de la biología y diversidad cultural
}

Castaño, Norma Constanza'

\section{Categoría: 1.}

\section{Resumen}

El conocimiento en ciencia y tecnología es cada vez más importante en el mundo actual, pero las investigaciones muestran dificultades en guiar a los estudiantes de diversos orígenes hacia su aprendizaje significativo y tendencias como la estandarización de los currículos son altamente inequitativas y excluyentes.

Tener en cuenta el contexto cultural, podría proporcionar los escenarios para que dicha enseñanza sea útil. Estos planteamientos pueden constituirse en base para renovar los procesos de formación desde una perspectiva epistemológica, e incluso darle una connotación distinta a la didáctica.

Estas reflexiones corresponden a los desarrollos de la tesis de doctorado "Concepto de vida, cosmogonía Uitoto, enseñanza de la Biología y diversidad cultural: perspectivas ontológicas y epistemológicas.

\section{Palabras clave}

Enseñanza de la biología, contexto, diversidad cultural.

De acuerdo con Lee y Luyks, (Citado en: Abell y Lederman. 2008, p. 171 - 191), desde una perspectiva multiculturalista, el conocimiento en ciencia y tecnología es cada vez más importante en el mundo actual; sin embargo las investigaciones acerca del conocimiento sobre los profesores de ciencia y/o la diversidad de los estudiantes muestran que hay dificultades en guiar a los estudiantes de diversos orígenes hacia el aprendizaje significativo de las ciencias y que tendencias como la estandarización de los currículos son altamente inequitativas y excluyentes (McNeil, 2000)

1 Estudiante Doctorado en Educación - sede Universidad Distrital Francisco José de Caldas; profesora investigadora Universidad Pedagógica Nacional. Correo: ccastano@pedagogica.edu.co 
Revista Tecné, Episteme y Didaxis: TED. Año 2014, Número Extraordinario. ISSN Impreso: 0121-3814, ISSN web: 2323-0126

Memorias, Sexto Congreso Internacional sobre Formación de Profesores de Ciencias. 08 al 10 de octubre de 2014, Bogotá

A nivel internacional Molina (2010) muestra que Hills (1989) considera que muchas veces para los estudiantes, los conceptos científicos son extraños y que en términos de aprendizaje, se puede considerar que puede mejorarse a través de actividades de intercambio cultural. Wilson (Citado en Molina, 2010) considera que para que la enseñanza de las ciencias sea efectiva, se debe tomar en cuenta explícitamente el contexto cultural, el cual, podría proporcionar los escenarios para que dicha enseñanza sea útil .

Molina (2010) plantea que es necesario implementar en la educación en ciencias el reconocimiento de la diversidad cultural, de modo que se enriquezcan las perspectivas conceptuales y epistemológicas con enfoques semánticos, culturales e históricos. Alude igualmente la necesidad de realizar investigaciones que permitan comprender tal fenómeno, para lo cual se requieren enfoques contemporáneos sobre el conocimiento, que lo entiendan más como una actividad orientada culturalmente; así se puede asumir que la educación de las ciencias de la naturaleza requiere ser comprendida dentro de un contexto cultural específico, porque la apropiación y construcción conceptual dependen también de los valores, de las decisiones, las creencias sobre lo que es verdadero, creíble, cognoscible, lógico, para el sujeto que conoce.

De otro lado, se considera que los retos de la educación en biología y particularmente de la formación de maestros, están en establecer relaciones entre las formas políticas contemporáneas, la educación y la búsqueda de alternativas posibles en contexto de lo que somos. Gestar propuestas alternativas que involucren a todos los sectores de la sociedad, como un ejercicio de libertad y solidaridad humana. Abordar la globalización, el posdesarrollo y la sustentabilidad ecológica, en formas social y políticamente efectivas (Castaño, 2012).

En este cuestionamiento inciden aspectos como:

- El antagonismo existente entre el conocimiento acerca de lo vivo, detentado por la Biología y los conocimientos ancestrales indígenas, que también han demostrado ser valiosos y eficaces.

- La necesidad de que el docente propicie procesos de aprendizaje, que atiendan las distintas cosmovisiones, lo cual exigiría que el aula pase de ser espacio de discriminación y de sanción, de transmisión y repetición, a constituirse en lugar de encuentro y construcción intersubjetiva. 
Revista Tecné, Episteme y Didaxis: TED. Año 2014, Número Extraordinario. ISSN Impreso: 0121-3814, ISSN web: 2323-0126

Memorias, Sexto Congreso Internacional sobre Formación de Profesores de Ciencias. 08 al 10 de octubre de 2014, Bogotá

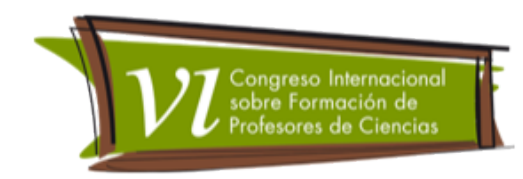

- La necesidad de transformar las preguntas que invariablemente guían la educación en biología y reconocer diversas fuentes de conocimiento.

- Considerar que la razón está influenciada por la cultura; hay tantas verdades como culturas, clases sociales, intereses y creencias existan.

- La contribución que se puede hacer desde la formación de docentes en Biología, a la construcción de un país diverso, biológica y culturalmente.

\section{Enseñanza de la biología en Colombia y diversidad cultural}

Reconocer quiénes somos, es un asunto prioritario, como base que nos permitiría aceptar que existen otras lógicas, otras estéticas, otras mentalidades, otras cosmovisiones, que nos pueden enriquecer como país. Con la Constitución de 1991, los derechos fundamentales de los grupos étnicos se han afianzado y ha surgido una nueva relación con el Estado colombiano a partir de la aceptación de la diversidad cultural: "El gran agregado de la Constitución de 1991 fue la concreción y expresión normativa de la necesidad de fomentar en toda la sociedad relaciones de mutualidad e interculturalidad, en vez de las de dominación de la sociedad hegemónica hacia las minorías étnicas" (Bodnar, 2005, p.9). Este reconocimiento hace surgir un nuevo tipo de relación frente a la diversidad étnica, pasando de relaciones de tipo vertical a relaciones horizontales con grupos de población considerados como minoritarios, lo que genera la necesidad de asumir un enfoque diferencial que valore y reconozca la diversidad. Entre este reconocimiento se manifiesta el derecho a una formación que respete y propicie la identidad cultural (Art. 68); ello implica desarrollar procesos educativos que hagan visibles a estos grupos étnicos, para que sus reivindicaciones y necesidades de participación puedan ser atendidas debidamente.

De una $u$ otra manera es necesario reconocer que existen otras perspectivas en lo que se refiere a la relación educación en ciencias y cultura. Es así como Cobern \& Loving (2001) se preguntan si la ciencia es universal; aluden que las explicaciones de una "buena ciencia" siempre serán universales, incluso si se trata del conocimiento indígena que puede ser valorado por sus propios méritos y puede jugar un papel fundamental en la educación científica.

Plantean que toda ciencia es socialmente contingente y culturalmente integrada y que otras perspectivas epistemológicas como el multiculturalismo (Stanley \& Brickhouse, 1994), el poscolonialismo (McKinley, 1997), y la postmodernidad 
Revista Tecné, Episteme y Didaxis: TED. Año 2014, Número Extraordinario. ISSN Impreso: 0121-3814, ISSN web: 2323-0126

Memorias, Sexto Congreso Internacional sobre Formación de Profesores de Ciencias. 08 al 10 de octubre de 2014, Bogotá

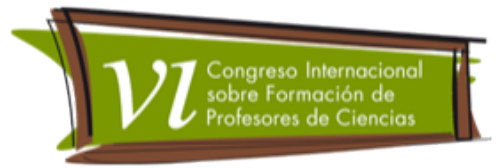

(Lyotard, 1995) desafían la sabiduría convencional occidental en lo que se refiere a la relación entre la ciencia occidental y la cultura. En la educación, Hodson (1993, citado en: Cobern \& Loving, 2001, p. 54) sostiene que los programas de ciencias a menudo "retratan la ciencia que se encuentra ... exclusivamente de un contexto cultural occidental. El mensaje implícito para el currículo es que la única ciencia es la ciencia occidental ...", por ende para quienes reciben este mensaje, especialmente si provienen de comunidades étnicas, ello podría significar desvalorización de su propia identidad y de sus propios conocimientos y fundamentalmente apatía hacia el aprendizaje de las ciencias.

En términos educativos, lo plantea una maestra "Mi objetivo sería que todos los niños sientan que tienen un patrimonio muy importante. No importa cuál sea el patrimonio de procedencia. Y que para ser un científico, no significa que usted tiene que ser de una raza en particular o cualquier género en particular ni de ninguna cultura en particular, sino que todas las personas han contribuido al cuerpo de conocimiento que llamamos ciencia. (Smithsonian Institution, 1996, citado en Cobern \& Loving, 2001, p. 56).

El problema, plantean Cobern y Loving (2001), es que no hay ninguna versión perfecta de la ciencia que claramente represente a todas las modalidades de la ciencia, en el pasado y en el presente, y con la misma claridad elimine todo aquello que los científicos consideran que no es ciencia.

\section{La enseñanza de la biología en Colombia}

En una investigación realizada por Chona \& Castaño \& Cabrera (1998), se plantea que la enseñanza de la Biología en Colombia ha sido influenciada por elementos de poder y de saber provenientes de diferentes instituciones normalizadoras; los enfoques con los que se ha abordado la enseñanza, provienen más de la estructuración de elementos políticos, administrativos y normativos que del establecimiento de criterios sobre lo que debe ser la función de la enseñanza de la Biología en un país como Colombia.

Se resalta, que a pesar de la manifiesta institucionalización de la enseñanza de la Biología, aún hoy existen insuficiencias teóricas y falta una práctica pedagógica creada a partir de nuestros propios elementos culturales. Se supone que se han privilegiado los esquemas de racionalidad de sociedades, donde el saber biológico ha tenido una historia fecunda y la enseñanza ha sido objeto de reflexión permanente. Es urgente construir un espacio para pensar nuestra historia 
Revista Tecné, Episteme y Didaxis: TED. Año 2014, Número Extraordinario. ISSN Impreso: 0121-3814, ISSN web: 2323-0126

Memorias, Sexto Congreso Internacional sobre Formación de Profesores de Ciencias. 08 al 10 de octubre de 2014, Bogotá

en relación con un sistema de enseñanza que debe crear nuevos modos de pensar la formación de sujetos en un contexto cultural propio.

Estos planteamientos pueden constituirse en base para renovar los procesos de formación desde una perspectiva epistemológica, e incluso darle una connotación distinta a la didáctica, al considerar no una historia sino las historias de las ciencias en relación con las didácticas con elementos como los siguientes:

- El conocimiento no surge de ideas abstractas, proposicionales, se construye en contextos socioculturales y tiene connotaciones ideológicas, en las que entra en juego el poder.

- Ubicar al sujeto humano como constructor de conocimiento, inserto en un contexto social que le genera situaciones que constituyen un sistema de significaciones y relacionar el desarrollo de sus procesos cognoscitivos con la epistemología de las ciencias, desde una historia propia, la nuestra.

- Darle sentido a la experiencia en la construcción de conocimientos, desde los mismos procesos cognoscitivos.

- La práctica vista como una serie de acciones que se constituyen en punto de partida para generar procesos de conocimiento.

- Concepciones de mundo que no se cuestionan y que condicionan la manera de comprender los fenómenos.

- El conocimiento no es universal, es diverso, cambia de acuerdo con el tipo de sociedad, con el tipo de cultura y con la época.

- Un conjunto de relaciones sociales, culturales y de poder que condicionan, los marcos de investigación y unas manera de pensar.

Es evidente que desde esta perspectiva incluso, se puede pensar en contribuir al reconocimiento de las culturas y de la diversidad en un país como Colombia que se considera biodiverso, pluriétnico y multicultural. Seguramente desde aquí puede surgir la interculturalidad como un elemento clave para la didáctica, como alternativa que reconoce otras formas de pensamiento, otras prácticas y otras formas de hacer.

\section{Referentes bibliográficos}

Abell, S. Y Lederman, N. (2007). Handbook of research on science education. Tomo 1. New York: Routledge. 
Revista Tecné, Episteme y Didaxis: TED. Año 2014, Número

Extraordinario. ISSN Impreso: 0121-3814, ISSN web: 2323-0126

Memorias, Sexto Congreso Internacional sobre Formación de Profesores de Ciencias. 08 al 10 de octubre de 2014, Bogotá

Bodnar, Y. (2005). Apuntes sobre la diversidad cultural y la información sociodemográfica disponible sobre los pueblos indígenas de Colombia. Notas de Población, Año XXXI, núm. 79, Naciones Unidas, CEPAL, Santiago de Chile.

Castaño, N.C. (2012). La enseñanza de la Biología en un país biodiverso, pluriétnico y multicultural. Aproximaciones epistemológicas. En: Revista BioGrafía Número extraordinario. Mayo de 2012. Pp.560-586., N. C. (2009). Construcción social de universidad para la inclusión: la formación de maestros con pertinencia y en contexto, desde una perspectiva intercultural [Colombia] pp. 183 - 206. En: Mato, Daniel. Educación Superior, Colaboración Intercultural y Desarrollo Sostenible/Buen Vivir. UNESCO IESALC.

Chona, G., Castaño, N.C., Cabrera, F., Y Otros. (1998). Lo que nos dice la historia de las enseñanza de la biología en Colombia- Una aproximación. Revista Tecne, Episteme y Didaxis, No 4 pp 5-10

Cobern, W., Loving, C. Defining "Science" in a multicultural world: Implications for Science Education. En: Science Education, 85:50-67, 2001.

Mcneil, L.M. (2000). Creating new inequalities: contradictions of reform. Phi Delta Kappan,81, 729-734.

Molina, A. (2010). Una relación urgente: enseñanza de las ciencias y contexto cultural. Revista EDUyT. Vol. 1, enero - junio. 